\title{
Metamorfosis regional acelerada, articulación territorial y financiarización en una ciudad intermedia mexicana: el caso de Querétaro
}

Accelerated Regional Metamorphosis, Territorial

Articulation and Financialization in a Mexican

Intermediate City: The Queretaro Case

Metamorfose regional acelerada, articulação

territorial e financeirização em uma cidade

intermediária mexicana: o caso de Querétaro

Carlos Daniel Martner-Peyrelongue*

Recibido: 29 de noviembre de 2019

Aprobado: 13 de mayo de 2020

https://doi.org/10.12804/revistas.urosario.edu.co/territorios/a.8285

Para citar este artículo:

Martner-Peyrelongue, C. D. (2020). Metamorfosis regional acelerada, articulación territorial y financiarización en una ciudad intermedia mexicana: el caso de Querétaro. Territorios, (43-Especial), 1-26.

* Coordinador de Transporte Integrado y Logística del Instituto Mexicano del Transporte. Correo electrónico: martner@imt. mx ORCID: https://orcid. org/0000-0002-7676https://doi.org/10.12804/revistas.urosario.edu.co/territorios/a.8285 
Palabras clave

Ciudad intermedia; financiarización; territorio; suelo rural; inmobiliario; Querétaro; Colón.

Keywords

Intermediate city; financialization; territory; rural land; real estate; Querétaro; Colón.

Palavras-chave

Cidade intermediária; financeirização; território; solo rural; imobiliário; Querétaro;

Colón.

\section{tersitorias 43-Especial}

RESUMEN

En décadas recientes algunas ciudades intermedias mexicanas manifiestan un elevado dinamismo económico cuya expresión territorial más evidente ha sido una expansión dispersa y difusa en espacios cada vez más amplios, los cuales solían considerarse eminentemente rurales. Este es el caso de la ciudad de Querétaro, y su área de expansión dispersa sobre espacios rurales de El Marqués y, especialmente, de Colón. En este sentido, el presente trabajo tiene como propósito analizar y caracterizar la transformación socioterritorial de esta zona de expansión de una ciudad intermedia mediante un enfoque teórico-metodológico de tipo estructural-sistémico, cuya unidad de análisis se ubica más allá de la ciudad o metrópolis al incluir los espacios rurales vinculados, en los cuales los recientes esquemas de financiarización del sector inmobiliario generan nuevas configuraciones y desigualdades espaciales, con un resultado que conduce a una ocupación dispersa y desordenada del territorio. Allí las premisas de rentabilidad de los inversores rebasan constantemente los criterios de un ordenamiento urbano-regional coherente que privilegie el desarrollo local y ambiental sostenible a largo plazo.

\section{ABSTRACT}

In recent decades, some intermediate Mexican cities show a high economic dynamism whose most evident territorial expression has been a dispersed and diffuse expansion over increasingly wideranging spatial areas that generally were considered eminently rural. This is the case of the city of Querétaro and its expansion sphere, scattered over the rural areas of El Marqués and, especially, Colón. In this sense, this work analyses and characterizes the socio-territorial transformation of this expansion area of an intermediate city, through a theoretical-methodological approach of a structural-systemic type, whose unit of analysis goes beyond the city, it includes its linked rural spaces, in which the recent financialization schemes of the real estate sector generate new configurations and spatial inequalities that lead to a dispersed and disorderly occupation of the territory, where the premises of profitability of investors have replaced any coherent urban-regional planning criteria that privileges long-term sustainable local and environmental development.

\section{RESUMO}

Em décadas recentes algumas cidades intermediárias mexicanas manifestam um elevado dinamismo econômico cuja expressão territorial mais evidente tem sido uma expansão dispersa e difusa sobre âmbitos espaciais cada vez mais amplos, os quais costumavam considerar-se eminentemente rurais. Este é o caso da cidade de Querétaro, México, e sua área de expansão dispersa sobre âmbitos rurais da zona de El Marqués e, especialmente, de Colón. Neste sentido, o presente trabalho tem como propósito analisar e caracterizar a transformação socio-territorial desta zona de expansão de uma cidade intermediária, mediante um enfoque teórico-metodológico de tipo estrutural-sistêmico, cuja unidade de análise se localiza para além da cidade ou metrópole, ao incluir os espaços rurais vinculados, nos quais os recentes esquemas de financeirização do setor imobiliário geram novas configurações e desigualdades espaciais, com um resultado que conduz a uma ocupação dispersa e desordenada do território, onde as premissas de rentabilidade dos investidores têm substituído qualquer critério de ordenamento urbano-regional coerente que privilegie um desenvolvimento local e ambiental sustentável ao longo prazo. 


\section{Introducción}

En las últimas décadas, México presenta una profunda metamorfosis en su estructura urbano-regional, donde enormes transformaciones socioterritoriales están modificando rápidamente las actividades productivas, los empleos, las relaciones sociales y las formas culturales y de vida de miles de personas de escasos recursos, cuyo hábitat natural se ha trastocado de manera radical por un acelerado proceso de urbanización, que incluye enormes espacios considerados rurales hasta hace poco tiempo.

Esto se observa con mayor fuerza en regiones o territorios dinámicos con crecimiento de nuevas actividades financieras, inmobiliarias, industriales y de servicios vinculadas generalmente a cadenas productivas globalizadas, cuya localización se está dando mediante una creciente expansión urbana, que se desdobla no solo sobre sus periferias inmediatas, sino sobre un ámbito regional más extenso. Tal es el caso del municipio de Colón, cuya cabecera municipal se localiza a 60 kilómetros de la ciudad de Querétaro, México, un espacio que solía considerarse eminentemente rural, pero que se está transformado aceleradamente como parte de un proceso de expansión dispersa de la zona metropolitana de la ciudad de Querétaro, donde la mercantilización creciente del espacio a través de los nuevos esquemas de financiarización de las actividades inmobiliarias, asociados a una fuerte demanda de suelo para actividades industriales, comerciales, de servicios y de vivienda propiciadas por el dinamismo económico de la región en la última década, generan nuevas configuraciones $\mathrm{y}$ desigualdades territoriales.

En este contexto, se parte de la hipótesis de que el fenómeno urbano en ciudades intermedias dinámicas no puede ser cabalmente entendido sin incorporar al análisis su articulación con el ámbito regional extendido, muchas veces difuso y disperso debido a la creciente acción de actores privados del sector inmobiliario — cada vez más integrados con el sector financiero en un binomio sumamente amalgamado e indisoluble- que participan en la mercantilización del suelo y en la permanente transformación de sus usos ante la ausencia de procesos de planeación u ordenación territorial efectivos por parte de los gobiernos locales, regionales o estatales. Lo cierto es que actualmente es difícil entender estas nuevas configuraciones territoriales “a través de los conceptos tradicionales relacionados con la urbanidad, el metropolitanismo o el esquema binario urbano/rural, que presuponen una separación espacial coherente de los distintos tipos de asentamientos" (Brenner, 2013, p. 44).

En este sentido, el objetivo del presente trabajo consiste en caracterizar la acelerada transformación socioterritorial de localidades rurales de la región de El Marques y, especialmente, de Colón (por ser un municipio más alejado y rural), bajo territarias 43-Especial 


\section{territorias} 43-Especial un patrón de expansión extendida y difusa de la Zona Metropolitana de Querétaro sobre ámbitos cada vez más distantes del núcleo central de esta ciudad intermedia mexicana, donde se producen vertiginosos cambios de los usos del suelo y de las actividades económicas derivados de una creciente incorporación de mecanismos de financiarización de las actividades inmobiliarias y económicas dispersas, que tienden a articularse mediante la expansión constante de la infraestructura y los sistemas regionales de transporte.

Metodológicamente, se busca contribuir al análisis territorial con un enfoque estructural-sistémico, que ubica la unidad de análisis más allá de los límites de lo urbano o metropolitano, en un ámbito de comprensión amplio de los nuevos fenómenos de vinculación entre áreas rurales y urbanas, que traen adosados procesos de fragmentación e integración desigual de vastos sectores no siempre adaptados a los nuevos patrones socioterritoriales que demandan estas nuevas relaciones sociales.

Este enfoque apunta hacia un análisis deductivo a partir de la integración de elementos cualitativos y cuantitativos, derivados de la información y datos recopilados en campo para articular el planteamiento teórico con base en el enfoque sistémico de redes y flujos (Delgado, 1998; Espino, 1995; Veltz, 2014), así como del análisis de las tendencias hacia la urbanización planetaria en la actual fase de la economía-mundo capitalista, cuyo sustento conceptual básico se encuentra en autores como De Mattos y Fuentes (2012), De Mattos (2016), Daher (2013) Brenner (2013), Brenner y Schmid (2016) y Méndez (2018), entre otros.

\section{Expansión dispersa de la Zona Metropolitana de Querétaro}

\section{Concentración y dispersión: viejas tendencias, nuevas configuraciones}

Ciertamente, la concentración de la población y las actividades económicas, sociales, políticas y culturales en ámbitos territoriales específicos o selectos dentro de la geografía del planeta ha sido históricamente un patrón dominante dentro del modo de producción capitalista, pero también la dispersión en términos territoriales es un proceso que viene adosado a los efectos y contradicciones propias de la aglomeración.

En efecto, además de las notables ventajas de la concentración espacial en la gestión y eficiencia de los procesos productivos, en el desarrollo de la cooperación compleja dentro de las unidades industriales, comerciales o de servicio y en el necesario proceso de socialización de las fuerzas productivas que ha sido fundamental en la esfera económica, la aglomeración ha generado externalidades o, mejor dicho, ha desatado contradicciones propias del modelo de acumulación que propician tendencias hacia la dispersión. Tal como, en su momento lo explicó Pradilla (1984), las desventajas 
de la aglomeración provienen, en buena medida, de la anarquía que produce en el crecimiento de las ciudades el carácter privado de la propiedad de los medios de producción y de la apropiación de la producción social y, con ello, el carácter individual de las decisiones de apropiación del territorio y de la producción de objetos inmobiliarios.

En este sentido, cabe decir que la concentración y la dispersión son viejas tendencias en la configuración del territorio durante el desarrollo del capitalismo, donde generalmente las fuerzas centrípetas han controlado y subordinado a las fuerzas centrifugas de la dispersión. No obstante, lo que se modifica a través de las diferentes fases de desarrollo del sistema es la intensidad, la forma y las cualidades en que se manifiestan la concentración y la dispersión territorial y los efectos que tienen en el funcionamiento del modelo o fase de acumulación en turno. En este contexto, es posible hablar de nuevas tendencias en los procesos de organización del territorio (Martner, 2016).

Es así como en la actual fase de globalización, donde el capital financiero se ha vuelto hegemónico, invadiendo, controlando e imponiendo sus prioridades sobre las demás esferas del capital y de las actividades económicas, en lo que muchos autores han llamado la fase de financiarización de la economía-mundo capitalista propiciada por la integración global de los mercados financieros (Brenner, 2013; Daher, 2013; De Mattos, 2016;
Delgadillo, 2016; Méndez, 2018), se han potenciado y acelerado, como nunca antes, los procesos de urbanización extendida y dispersa, que hacen cada vez más difusa la frontera entre lo que convencionalmente se ha conocido como lo urbano y lo que se encuentra más allá de sus límites: lo externo, lo rural.

Es por ello por lo que las delimitaciones empíricas entre lo urbano y lo rural pierden vigencia y tienen cada vez menor fuerza explicativa dentro de los estudios de la geografía y el territorio, en tanto avanzan las visiones de un mundo donde no caben tales divisiones tajantes, donde los procesos y los territorios se interconectan, donde todo se urbaniza, aunque visualmente mantenga la apariencia de localidades menores, villorrios y áreas de campo.

En efecto,

la ciudad está en todos lados y en todas las cosas. Si el mundo urbanizado es ahora una cadena de áreas metropolitanas conectadas por lugares/corredores de comunicación (aeropuertos y líneas aéreas, estaciones y ferrocarriles, estacionamientos y carreteras, telepuertos y autopistas informáticas), ¿qué queda por fuera? ¿Acaso el pueblo, la aldea, el campo? Tal vez, pero solo parcialmente. Las huellas de la ciudad están en todos estos lugares como personas que viajan a diario entre su hogar y el trabajo, y también en forma de turistas, trabajo a distancia, medios de comunicación y urbanización de los modos de vida. La división tradicional territarios 43-Especial 
entre la ciudad y el campo ha sido destruida (Amin \& Thrift, 2002, p. 1).

En sintonía con lo señalado y abonando a su tesis sobre la urbanización planetaria, Brenner (2013) agrega que, en el ámbito de una urbanización que comprende cada vez más tanto la concentración, como la extensión,

las aglomeraciones se forman, expanden, contraen y transforman de manera continua, pero siempre a través de densas redes de relaciones con otros lugares, territorios y escalas, incluidos los ámbitos tradicionalmente clasificados como ajenos a la condición urbana. Estos últimos abarcan, por ejemplo, pueblos pequeños y medianos, aldeas situadas en regiones periféricas y zonas agroindustriales (pp. 61-62).

Por ello concluye que,

ya no hay ningún exterior del mundo urbano; lo no urbano se ha interiorizado en gran medida dentro de un proceso planetario, pero desigual de urbanización. En estas condiciones, el binarismo urbanorural es una base cada vez más confusa para descifrar las morfologías, contornos y dinámicas de la reestructuración socioespacial en el capitalismo de principios del siglo XXI (Brenner \& Schmid, 2016, p. 332).

Precisamente, la zona metropolitana de la ciudad de Querétaro se encuentra dentro de esta dinámica de expansión y desdoblamiento espacial de actividades típicamente urbanas sobre extensas áreas consideradas previamente como exteriores. La región de Colón, ubicada a 60 kilómetros al este de la urbe, donde se asientan localidades menores en medio de un paisaje eminentemente rural, asiste a una acelerada metamorfosis territorial, donde emergen simultáneamente islotes de urbanidad en forma dispersa y difusa, constituidos por zonas industriales, de actividades logísticas y servicios, así como conjuntos residenciales para diferentes segmentos sociales, en cuyo desarrollo han jugado un rol protagónico los recientes procesos de financiarización.

\section{Dinamismo y transformación regional de Querétaro}

El tema de la acelerada expansión urbana impulsada fuertemente por los procesos de finaciarización de las actividades inmobiliarias ha sido relacionado generalmente con las grandes urbes, capitales y centros metropolitanos en diversos países y regiones del mundo, ya sea en los países centrales o en los de la semiperiferia y la periferia dentro del actual sistema mundial capitalista (Daher, 2013; de Mattos, 2016; Méndez, 2018). No obstante, pareciera que, varias ciudades intermedias con mayor dinamismo y crecimiento económico están entrando también en estos procesos de expansión territorial difusa y en las lógicas del capitalismo financiero. 
En México, desde hace un par de décadas, las llamadas ciudades intermedias han adquirido creciente importancia dentro de la estructura urbano-regional del país (Martner, 2015). Al respecto, el Consejo Nacional de Población ha reportado que existen 60 zonas metropolitanas, de las cuales solo cuatro corresponden a la definición de grandes ciudades o megalópolis (Ciudad de México, Guadalajara, Monterrey y Puebla). El resto se compone de ciudades medias, con poblaciones que oscilan entre los 150 mil y 1.5 millones de habitantes (CONAPO, 2011).

Diversos estudios sobre las llamadas ciudades medias mexicanas (Sánchez \& Propin, 2001; Anzaldo \& Rivera, 2006) muestran que estas

se caracterizan por ser los nuevos centros urbanos de mayor crecimiento demográfico, así como poseer una mayor atracción para la población migrante que las grandes zonas metropolitanas, como tradicionalmente se había presentado. Este patrón de urbanización se ha mantenido desde principios del siglo XXI (Álvarez, 2011, pp. 92-93).

En este contexto, cabe señalar que el crecimiento de las ciudades intermedias en muchos casos ha desbordado los límites municipales, mostrando una creciente expansión sobre sus periferias. No obstante, recientemente el proceso de expansión abarca un ámbito espacial mucho más amplio y poroso, donde no solo está contenido el continuo paisaje urbano, sino múltiples localidades rurales vinculadas fuertemente a la urbe (Martner, 2015).

En México, la ciudad de Querétaro, ubicada a $220 \mathrm{~km}$ al norte de Ciudad de México, es un ejemplo significativo de este tipo de dinámica territorial. Desde la década de los 90, se hizo cada vez más manifiesto el desbordamiento y conurbación de la ciudad hacia los municipios aledaños de Corregidora y El Marques, con lo cual se conformó la llamada Zona Metropolitana de Querétaro, misma que se mantuvo bastante compacta hasta mediados de la primera década del siglo XXI, mientras que en la segunda el patrón de poblamiento se ha vuelto más disperso y difuso, abarcando vastos espacios eminentemente rurales al este del municipio de El Marqués y sobre todo en el colindante municipio de Colón, caracterizado por ser históricamente más rural y también más distante respecto al ámbito metropolitano en cuestión.

La población de esta zona metropolitana pasó de 550 mil habitantes, en 1990, a 1 millón 217 mil habitantes en 2015. Cabe señalar que, en la última década, hubo un crecimiento bastante moderado de la ciudad central (municipio de Querétaro) frente al dinamismo poblacional de las áreas periféricas con un patrón mucho más disperso de ocupación del territorio. Entre 2005 y 2015, el área urbana del municipio de Querétaro creció a una tasa media de $1.8 \%$ anual, en tanto que los municipios territarios 43-Especial 


\section{tersitarias} 43-Especial aledaños, por una parte, Corregidora, ubicado al sur oeste de la ciudad central y, por otra, El Marques, localizado al este, lo hicieron a tasas promedio anuales de $5.7 \mathrm{y}$ $7 \%$ durante el periodo de análisis (COESPO, 2017). Esta dinámica ha propiciado que actualmente la zona metropolitana de Querétaro concentre el $60 \%$ de la población del Estado de Querétaro.

Ahora bien, es importante señalar que este proceso de expansión dispersa y difusa se ha extendido hacia zonas todavía más alejadas del centro urbano, abarcando recientemente el municipio de Colón, que se localiza al este del municipio de El Marqués, el cual es de especial interés en este trabajo, dada la acelerada metamorfosis territorial que ha padecido en los últimos años a causa de una intensa participación de las nuevas formas de financiarización del sector inmobiliario. No obstante, dado que estos procesos no se circunscriben a los rígidos limites municipales, en el análisis precedente también son incorporados ejidos y comunidades rurales del municipio de El Marqués que presentan las mismas dinámicas de ocupación del territorio bajo el nuevo modelo financiarizado que afecta a Colón.

Por lo pronto, es preciso mencionar algunos datos relevantes del dinamismo económico reciente de la llamada Zona Metropolitana de Querétaro, incluyendo sus áreas de expansión recientes. Como se señaló, tal zona concentra el $60 \%$ de la población del Estado y su participación en el PIB es aún mayor: alcanza el $80 \%$ (INEGI, 2018).

Otro dato relevante es que la economía de este Estado crece a un ritmo considerablemente superior que el promedio nacional. Entre 2003 y 2017, la tasa de crecimiento media anual del PIB nacional fue de $2.3 \%$, mientras que la de Querétaro duplicó esta cifra al alcanzar un promedio de $4.7 \%$ anual. Este indicador se incrementó aún más en los últimos años, entre 2010 y 2017, el PIB queretano creció a una tasa promedio de $4.9 \%$ anual.

En este contexto, resulta necesaria una breve explicación de los sectores que sostienen tal dinamismo. Grosso modo se puede decir que la actividad económica queretana está basada en el crecimiento de los sectores secundario y terciario. A saber, los rubros de mayor peso en el PIB de esta región son la industria manufacturera, con el $29.2 \%$ del PIB; el comercio, con el $18.4 \%$; la industria de la construcción, con el $13.2 \%$; los servicios inmobiliarios, con el $8.9 \%$ y el transporte y almacenamiento, con el $6.2 \%$ (INEGI, 2018).

Más interesante aún es observar la dinámica de tales rubros durante lo que va de la presente década. Así, por ejemplo, entre 2010 y 2017 , mientras el PIB nacional de la industria manufacturera había crecido a una tasa promedio de $2.7 \%$, el de la industria manufacturera de Querétaro lo hizo a un ritmo notoriamente superior de $6.2 \%$ anual; por su parte, el PIB nacional de la industria de la construcción mantuvo 
durante este periodo un comportamiento discreto, alcanzando un promedio de $1.6 \%$ anual, en cambio el de Querétaro aumentó a una tasa de $6 \%$ anual; lo propio sucedió con el comercio al por mayor, donde el promedio nacional alcanzó el $4.7 \%$ anual, mientras el de Querétaro llegó a $6.5 \%$ anual. Por último, no debe dejar de mencionarse que el sector que está creciendo con mayor rapidez, tanto a nivel nacional como a nivel del Estado de Querétaro, es el de servicios financieros y seguros. Durante el periodo de análisis, el PIB nacional de este segmento se incrementó a una tasa promedio de $10.7 \%$ anual, mientras que en Querétaro alcanzó un vertiginoso crecimiento de $14.8 \%$ anual (INEGI, 2018), como presagio o constatación de un modelo de desarrollo donde penetra progresivamente la financiarización en el quehacer cotidiano de las actividades económicas regionales.

Ahora bien, todo este dinamismo tiene una expresión espacial que es necesario desentrañar para comprender los procesos, resortes y características de estas nuevas modalidades de ocupación del territorio, que se caracterizan por la mercantilización del suelo rural y la relativa facilidad para modificar los usos de esos suelos, en una época en la que se ha transitado de la planeación indicativa del periodo previo hacia la ordenación territorial por el mercado, con escasa incidencia práctica de políticas de planeación territorial sostenible por parte de las diversas instancias y niveles de gobierno, frente a las decisiones de rentabilidad de un sector inmobiliario crecientemente financiarizado.

\section{Metamorfosis regional acelerada en Colón, Querétaro}

\section{Contra-reforma agraria y mercantilización del suelo rural}

Un elemento clave dentro de la metamorfosis territorial acelerada de la zona de estudio consiste en la posibilidad de la mercantilización masiva del suelo rural, que previamente no existía, dado el carácter social de la tierra, según lo establecido en la legislación de la reforma agraria y el reparto de tierras a los campesinos, derivada de la Revolución mexicana de 1910. En efecto, dicha reforma creó un tipo de propiedad social de la tierra, llamada ejido, que se entregó en usufructo a campesinos de miles de localidades rurales en todo el país.

El ejido es una forma de organización social dotada de personalidad jurídica, constituida por una asamblea de socios (los ejidatarios) y autoridades representativas escogidas por ellos (comisarios ejidales) encargadas de vigilar el cumplimiento de su razón de ser, esto significaba, entre otras cosas, que la tierra debía ser cultivada por el titular de cada parcela del ejido, no podía mantenerse ociosa ni venderse ni alquilarse. De esta forma, un aspecto central de dicha reforma agraria fue que este tipo de propiedad social no podía enajenarse $y$, por lo tanto, no había forma territarios 43-Especial 
de incorporarla al mercado del suelo ni de transformar su uso, con lo que se inhibió durante décadas tanto la mercantilización del suelo rural, como la expansión dispersa y difusa de las ciudades, ya que solo se expropiaron partes de los ejidos por motivos de expansión de la mancha urbana en los bordes de las ciudades intermedias y grandes.

No obstante, todo este escenario comenzó a cambiar en la última década del siglo Xx, cuando se modificó sustancialmente al artículo 27 de la Constitución de los Estados Unidos Mexicanos que regula precisamente los temas relativos al campo y sus formas de propiedad. En 1992, en pleno auge de los gobiernos de corte neoliberal, fue aprobada la reforma a dicho artículo constitucional, cuyo cambio esencial fue permitir enajenar el ejido, con lo cual la propiedad social de la tierra puede convertirse en propiedad privada, mediante un proceso que implicó una serie de programas y pasos, algunos de los cuales llevó años implementar, para poder hacer funcional y efectiva esta nueva legislación.

Dicha reforma requirió cambios legales y reglamentarios; un instrumento clave de este proceso fue el Programa de Certificación de Derechos Ejidales y Titulación de Solares (PROCEDE),

instrumento del gobierno federal que otorga a los núcleos agrarios la función de llevar a cabo la regularización de la propiedad social a través de la entrega de certificados parcelarios y/o certificados de derecho de uso común, títulos de solares, etc., todo esto a favor de los individuos con derecho que integran los núcleos agrarios que así lo aprueben y soliciten (Montes, 2016, p. 87).

Ciertamente este proceso duró más de una década, puesto que consistió en hacer el deslinde topográfico de cada parcela individual y áreas de uso común en los miles de ejidos del país, base fundamental para poder otorgar la titulación de los predios a los individuos con derechos que posteriormente podrían decidir vender sus tierras al mejor postor.

Según Montes (2016), la forma mediante la cual se puede enajenar tierras ejidales a terceros es el principal resultado de la reforma al artículo 27 constitucional. El mecanismo mediante el cual se puede realizar este trámite se denomina Dominio pleno. La adopción de este es la acción que ejercita el ejidatario con la autorización previa de la asamblea ejidal de formalidades especiales, por virtud de la cual la parcela sobre la cual tiene derechos cambie al régimen de propiedad plena del ejidatario titular para sustraerla del patrimonio del ejido (Procuraduría Agraria, 2009). En otras palabras, se denomina Dominio pleno al trámite para solicitar la expedición de títulos de propiedad de origen parcelario y cambiarlos de propiedad social (ejido) a propiedad privada.

De acuerdo con entrevistas realizadas a ejidatarios en los municipios de El 
Marqués y Colón, el trámite para solicitar el Dominio pleno resulta bastante complejo para ellos, pues se requiere un conocimiento legal especializado sobre el tema. Para los habitantes de las localidades pertenecientes al área de estudio, y en general de todo el país, esto se vuelve un problema, por lo que tienen que recurrir a intermediarios especializados, que muchas veces son proporcionados por los grupos de desarrolladores inmobiliarios interesados en comprar sus tierras.

Después de la compra del suelo rural por una empresa o actor privado, se requiere realizar otro proceso legal para cambiar el uso del suelo, de acuerdo al giro que se le pretenda dar a este. En la zona de estudio normalmente se trata de desarrollos inmobiliarios industriales, comerciales, de servicios y residenciales bajo esquemas financiarizados tipo Real Estate Investment Trusts (REIT) - fondos o fideicomisos de inversión inmobiliaria-.

En la figura 1 se muestra el proceso para cambiar el uso de suelo rural de tierras que previamente tenían propiedad social (ejidos) a usos industriales, comerciales $\mathrm{o}$ residenciales.

Cuando ocurre el paso de compraventa del terreno, la tierra se enajena para que posteriormente el nuevo propietario pueda solicitar el cambio de uso del suelo en el municipio correspondiente. El trámite para cambiar el uso del suelo tiene que ser autorizado por el Cabildo del gobierno municipal y se denomina Dictamen de uso del suelo (Montes, 2016).

Lo cierto es que al final de este largo proceso, en los municipios considerados, hasta hace poco eminentemente rurales, ubicados a más de 50 kilómetros de la ciudad de Querétaro, la nueva Ley Agraria está permitiendo la mercantilización masiva del suelo de propiedad social, provocando cambios notables en la estructura territorial de esta región del país.

En otras palabras, las necesidades de suelo barato para la expansión extendida y difusa de nuevas áreas industriales, de servicios logísticos para la industria y

Figura 1. Proceso de transformación del suelo rural de propiedad ejidal a suelo de propiedad privada para usos distinto al rural

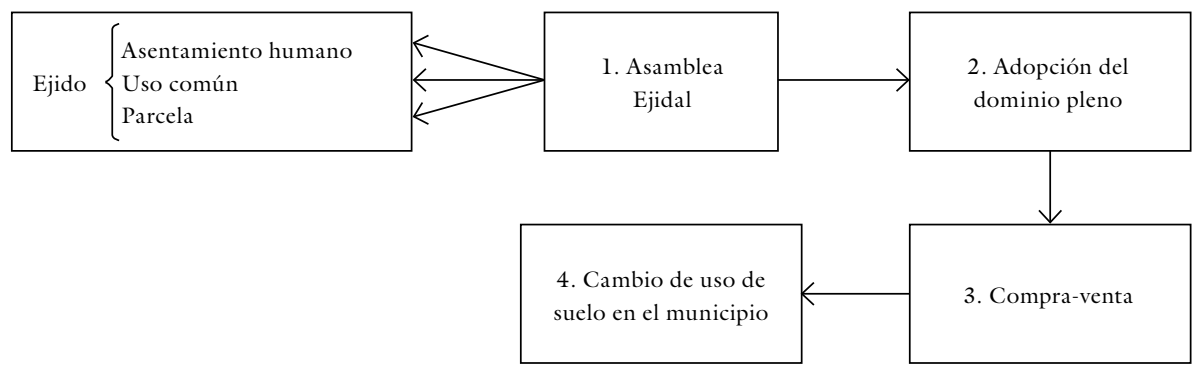

Fuente: Montes (2016). 
residenciales en medio del campo están siendo solventadas por la mercantilización del suelo rural (ejidal), generando una metamorfosis urbano-regional, estimulada y desarrollada por el vínculo entre el sector inmobiliario y el capital financiero nacional e internacional.

\section{Financiarización y expansión territorial acelerada en Colón}

\section{Expresión territorial de la vinculación del sector inmobiliario y financiero}

La financiarización ha sido descrita como una tendencia característica de la actual fase de desarrollo del capitalismo, caracterizada por la liberalización y globalización de la actividad económica, que deviene de una contradicción estructural del sistema, expresada en la recurrente sobreproducción y

generación de un excedente de capital que no puede ser plenamente reabsorbido mediante su reinversión en el ámbito productivo o el consumo y busca mayores tasas de rentabilidad en la esfera financiera. Reflejaría, por tanto, el deterioro de una actividad productiva que ve disminuir su rentabilidad, lo que empuja a los poseedores del capital a reorientar su destino en busca de nuevas fuentes generadoras de plusvalía más elevadas (Méndez, 2018, p. 36).
En este sentido, diversos autores (Harvey, 2012, de Mattos, 2016), al analizar los procesos de sobreacumulación en el capitalismo, identificaron un desplazamiento de fracciones importantes del capital del llamado circuito primario, relacionado con la producción de bienes y productos de diferente índole, hacia un segundo circuito de acumulación vinculado con la construcción, edificación y modificación del entorno físico.

Es decir, ese segundo circuito está constituido en buena medida por el sector inmobiliario, tal como en su momento lo reveló Lefebvre (1983), en su libro sobre la revolución urbana. La novedad en las últimas décadas consiste en la manera en que el capital financiero ha construido un entramado de diversos instrumentos y modalidades de inversión, todos ellos vinculados al mundo bursátil de accionistas anónimos y poseedores de bonos, poniendo un pie dentro, cuando no los dos, en el mercado de los negocios inmobiliarios y, por ende, tomando decisiones relevantes sobre la reconfiguración territorial de ciudades y regiones completas, sin utilizar necesariamente criterios de desarrollo urbano sostenibles y armónicos, sino principalmente mediante criterios de maximización de la rentabilidad de los inversionistas.

Es así como en la actualidad tanto en México, como en muchos países latinoamericanos, los principales desarrolladores inmobiliarios de parques industriales, centros comerciales, servicios y viviendas se 
encuentran estructurados bajo un patrón de organización financiarizado, ya sea porque han forjado alianzas estratégicas con inversionistas institucionales, porque han sido absorbidos por fondos de inversión o porque han formado fideicomisos de inversión y colocado bonos en los mercados bursátiles, entre otras modalidades.

Efectivamente, en las últimas décadas la financiarización del sector inmobiliario,

se nutre de los recursos de capital de los grandes inversionistas institucionales, la banca internacional, las sociedades de inversión y, en particular, de los fondos de inversión inmobiliaria y [de] infraestructura. Los fondos de inversión inmobiliaria vehiculizan muchas de esas colocaciones de capital, diversificando los portafolios y supuestamente disminuyendo los riesgos de los inversionistas. (...) Entre los fondos de inversión, los de pensiones se han convertido en uno de los principales actores en los mercados inmobiliarios, y sus inversiones resultan determinantes en términos sectoriales y territoriales (Daher, 2013 , p. 25).

De esta manera, se asiste a la incursión del capital financiero en la gestión y el control de muchas empresas de otros sectores de la economía, como es el caso del sector inmobiliario, imprimiéndoles su lógica y sus prioridades, mediante el desarrollo de formas de gobernanza corporativa que buscan cubrir, antes que nada, los objetivos inmediatos de rentabilidad financiera.
De hecho, en México las principales empresas y desarrolladores inmobiliarios que han estructurado alianzas con inversionistas institucionales (fondos de pensiones, fideicomisos de inversión en bienes raíces e infraestructura, bancos, compañías de seguros, etc.) tienen que desarrollar estándares de gobierno corporativo, pues cuando incursionan en los mercados financieros mediante emisiones de bonos o de certificados bursátiles deben garantizar metas y reglas claras en cuanto a la maximización y al reparto de los beneficios a los inversionistas. En este sentido, el gobierno corporativo termina siendo una representación de los intereses de tales inversionistas, que son quienes detentan, en buena medida, el capital social de las empresas inmobiliarias y, por ende, acaban por controlar la gestión y las decisiones estratégicas de las mismas. Qué activos adquirir, qué terrenos comprar, dónde construir y qué tipo de giro inmobiliario desarrollar son decisiones que tienen una manifestación física, que afectan al territorio, a las zonas urbanas y a los ámbitos regionales en su configuración, expansión y dispersión.

\section{Nuevas formas de financiarización inmobiliaria y transformaciones territoriales recientes en El Marqués y Colón, Querétaro}

El maridaje entre el sector inmobiliario y financiero está también presente en la zona de estudio. En la última década, se territorios 43-Especial 


\section{territorias} 43-Especial observa una multiplicación de la superficie de desarrollo de proyectos inmobiliarios de diversa índole, donde predominan los de tipo industrial, aunque también están presentes los de servicios logísticos y centros de distribución, los comerciales y los residenciales.

Aunado a la facilitación del proceso de mercantilización del suelo urbano analizado previamente, se desarrolló un nuevo instrumento financiero dedicado exprofeso a la inversión inmobiliaria en bienes raíces e infraestructura que multiplicó, en pocos años, el capital disponible para diversos tipos de inmuebles que van desde naves industriales, oficinas, centros comerciales, hoteles, universidades privadas, hasta centros de distribución de mercancías, terminales intermodales de transporte y carreteras de peaje, entre otros.

Efectivamente, desde 2011, en México se realizaron adecuaciones legales que permitieron crear los llamados Fideicomisos de Inversión en Bienes Raíces e Infraestructura, mejor conocidos como FIBRA. Este nuevo instrumento financiero es considerado como la versión mexicana de los REIT estadounidenses, los cuales se definen, en términos generales, como fondos de inversión en bienes inmuebles que emiten acciones o certificados en el mercado de valores.

Los FIBRA son instrumentos relativamente nuevos que cotizan en la Bolsa Mexicana de Valores (BMV) y permiten el financiamiento para la compra o construcción de bienes inmuebles en México.
Para constituir un FIBRA, los interesados deberán tener al menos el $70 \%$ de sus activos invertidos en bienes raíces, dedicarse a la compra o construcción de bienes inmuebles que se destinen al arrendamiento y distribuir entre los tenedores de certificados bursátiles al menos el $95 \%$ del resultado fiscal del ejercicio anterior. En efecto,

los bienes inmuebles que se construyan o adquieran deben destinarse al arrendamiento y no enajenarse (vender) antes de cuatro años contados a partir de la terminación de su construcción o de su adquisición. Y contar con altos estándares de Gobierno Corporativo (Celis, 2017, p. 1).

Con este tipo de instrumento, los inversionistas adquieren derechos, mediante la compra de certificados bursátiles, para recibir ingresos periódicos, que se obtienen de los arrendamientos, y a su vez tienen la posibilidad de hacerse de ganancias de capital (plusvalía) por la revalorización de los terrenos y edificaciones.

Desde 2011, cuando estos instrumentos entraron a la $\mathrm{BMV}$, hasta marzo de 2018, habían obtenido recursos por capitalización de más de 214 mil millones de pesos (11 mil millones de dólares). Es importante señalar que los FIBRA dan la oportunidad de participar en el financiamiento de proyectos inmobiliarios a inversionistas institucionales, como los fondos de pensiones, bancos, sociedades 
financieras, compañías de seguros y diversos fondos de inversiones autorizados por la legislación vigente. Actualmente, este instrumento de la financiarización tiene una gran liquidez a diferencia de las inversiones inmobiliarias tradicionales y está presente en casi la totalidad de los grandes desarrollos industriales, comerciales y residenciales de la zona de estudio.

En este sentido, baste mencionar algunos ejemplos significativos de desarrollos recientes en Colón que evidencian la manera superlativa en que han sido potencializados los desarrollos inmobiliarios financiarizados en la región. Durante la última década, se observan desarrollos inmobiliarios industriales tales como el Parque Aeroespacial de Querétaro, ubicado en el municipio de Colón, en predios que hace algún tiempo formaban parte del ejido de Galeras, donde participó Vesta Park, empresa mexicana que desarrolla, opera y arrienda edificios industriales y centros de distribución en México, en asociación con el fondo de inversiones inmobiliarias estadounidense GE Capital Real Estate. En 2018, este desarrollador inmobiliario inició la construcción de un segundo parque industrial en Colón, llamado Vesta Park Querétaro, con 102 hectáreas que previamente eran parte del ejido de Viborillas, en Colón (figura 3), dedicadas principalmente a la manufactura ligera y logística industrial, bajo una modalidad de arrendamiento similar al de los FIBRA.
Por su parte, la desarrolladora mexicana de parques industriales FINSA Real Estate Management, que tenía presencia en Querétaro desde la década de los 90, ha incursionado recientemente en la zona de estudio, desarrollando áreas para industria ligera, almacenaje y distribución sobre tierras que previamente eran predios ejidales. Durante la primera década del siglo XXI, dicha empresa realizó una alianza estratégica con AIG Global Real Estate, subsidiaria de American International Group, uno de los fondos de inversión inmobiliaria más importante de Estados Unidos, con el que logró duplicar el tamaño de su portafolio de edificios industriales en cinco años. En la presente década, ha colocado un portafolio vendido al Fideicomiso de Inversión FIBRA UNO para industria relacionada con el sector automotriz y ha desarrollado una sólida alianza con Walton Street Capital, otro importante fondo de inversión estadounidense, emitiendo Certificados de Capital de Desarrollo (CKD) y Certificados Bursátiles Fiduciarios Inmobiliarios (CBFI) en la BMV, que le han permitido acelerar sus inversiones y multiplicar su oferta de espacios industriales y de servicios logísticos en el país.

O'Donnell es otra empresa relevante en el desarrollo de zonas industriales en México que paulatinamente se ha adaptado a los esquemas de financiarización. A partir del 2003 firmó un programa de coinversión con la estadounidense 


\section{territorias} 43-Especial
Prudential Real Estate Investors (PREI) $\mathrm{y}$, de allí en adelante, avanzó en este tipo de alianzas que le han permitido multiplicar su oferta de espacios industriales y de servicios. Así es como a partir de 2013, O'Donnell administra el $65 \%$ de las propiedades del FIBRA Terrafina, un fideicomiso inmobiliario especializado en un portafolio industrial, constituido sobre todo por almacenes y propiedades de manufactura ligera. En 2014 y 2015 firmó coinversiones con AIG Global Real Estate para adquirir y desarrollar activos industriales y entre 2018 y 2019 incursionó en el desarrollo de activos de logística industrial con la colocación de CKD en la BMV. Cabe señalar que, en la zona de estudio, se está desarrollando el segundo polígono del parque industrial O'Donell Aeropuerto (emplazado en el municipio de El Marqués, en torno a los ejidos de Jesús María y Coyotiyos), dedicada a empresas de autopartes, sistemas electrónicos y logística (figura 3).

En esquemas similares de maridaje entre los desarrolladores inmobiliarios y el capital financiero se encuentran el Parque Industrial Aerotech, donde la división fiduciaria de Scotiabank en asociación con empresas locales y con American Industries, a través de sus divisiones Shelter Administrative Services e Industrial Real Estate, construyeron una zona dedicada sobre todo a la proveeduría para la industria aeroespacial y electrónica. Lo propio se puede decir del centro de distribución, almacenaje y servicios logísticos de $\mathrm{Fe}$ rroservicios y los parques industriales de Advance Real Estate, VYNMSA y el Parque Industrial Aeropuerto (PIA), todos ellos de muy reciente creación o en proceso de desarrollo en el municipio de Colón, Querétaro.

En un esquema financiarizado similar se produjo también el megadesarrollo inmobiliario sobre terrenos del ejido de La Esperanza, en Colón, de la filial de Universidad de Arkansas (Arkansas State University) que, más allá del campus universitario, incluye un amplio proyecto con áreas para el desarrollo comercial, residencial universitario y de servicios en medio de un entorno eminentemente rural (figura 2).

Con algunas diferencias en los esquemas de operación, están presentes también los desarrollos residenciales de viviendas de renta media y media-alta realizados por inmobiliarias como Centrury 21 , que en asociación con la banca comercial, otorgan créditos hipotecarios a los compradores de terrenos o viviendas $\mathrm{y}$, a diferencia de los FIBRA, los bienes inmuebles son puestos en venta, más que en arrendamiento.

En la región de estudio, se observa la construcción de nuevos conjuntos residenciales como el llamado Suburbio Santiago Aeropuerto, de 215 hectáreas, El Roble de 220 hectáreas y el Residencial Polo and Sky en el municipio de El Marqués (en lo que era parte del ejido Guadalupe La Venta), entre otros. En todos los casos se 


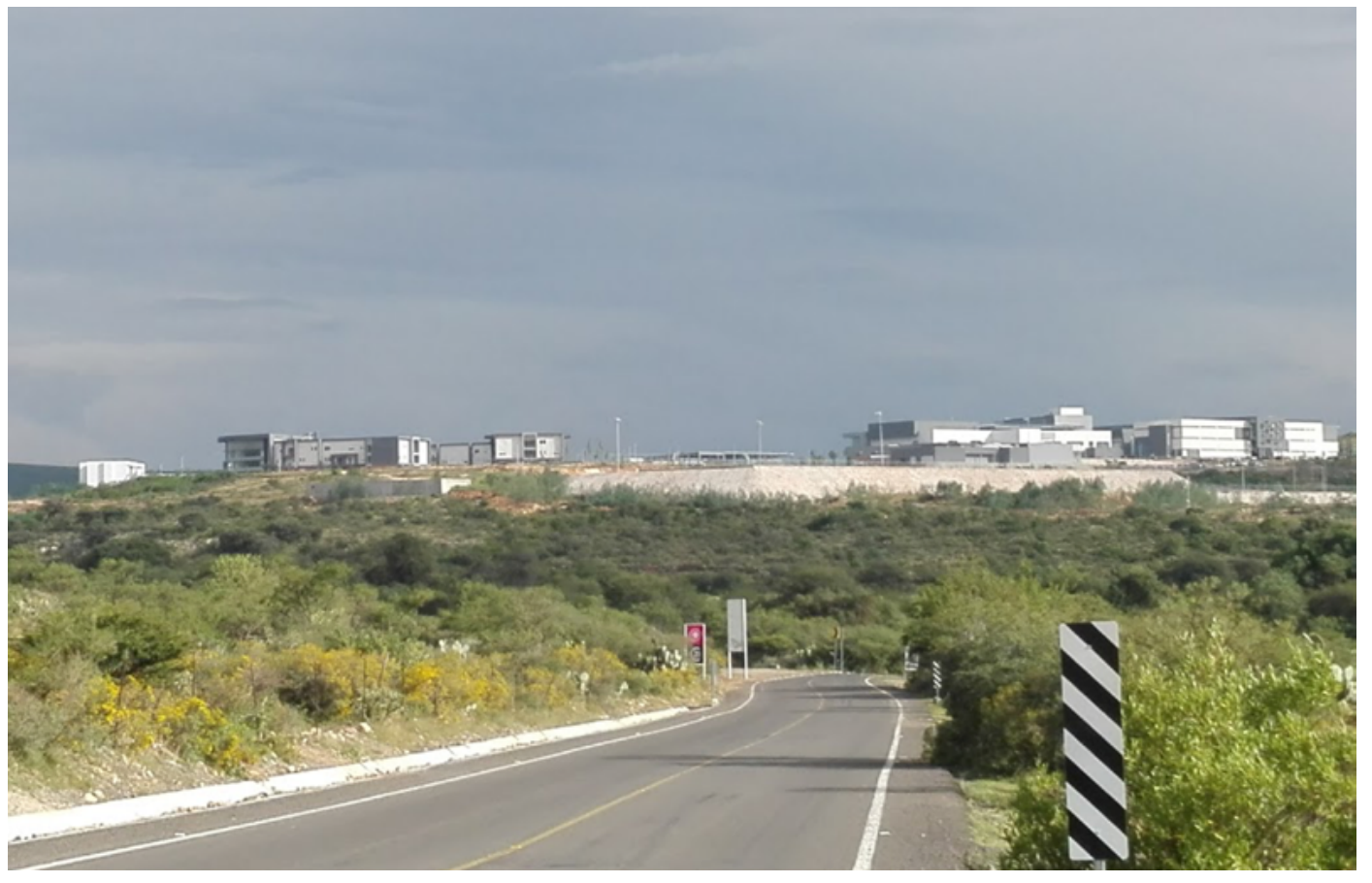

producen sobre emplazamientos dispersos, sin una lógica clara de planeación, compactación urbana u ordenación territorial, en terrenos que han sido adquiridos a exejidatarios o a pequeños propietarios de suelo rural y, posteriormente, sometidos al proceso de cambio de uso del suelo.

\section{Dispersión, diversificación de} actividades y usos del suelo. Hacia un territorio más flexible y adaptable

Este proceso de rápida transformación en las formas de gestión, en las magnitudes de los capitales incorporados a la construcción y en la rapidez con que los desarrolladores inmobiliarios financiarizados han incursionado en la zona de expansión de la ciudad intermedia mexicana de Querétaro y, en particular, en la llamada microregión de Colón, presenta una suerte de collage rururbano donde es observable una enorme dispersión de actividades y mezclas de usos del suelo de diversa índole.

Tal como se observa en la figura 3 , así como en las diversas imágenes de la zona en cuestión, se transita por paisajes sumamente cambiantes, donde se combinan territorios 43-Especial 
Figura 3. Expansión difusa de la Zona Metropolitana de Querétaro. Vista parcial de los municipios de El Marqués y Colón

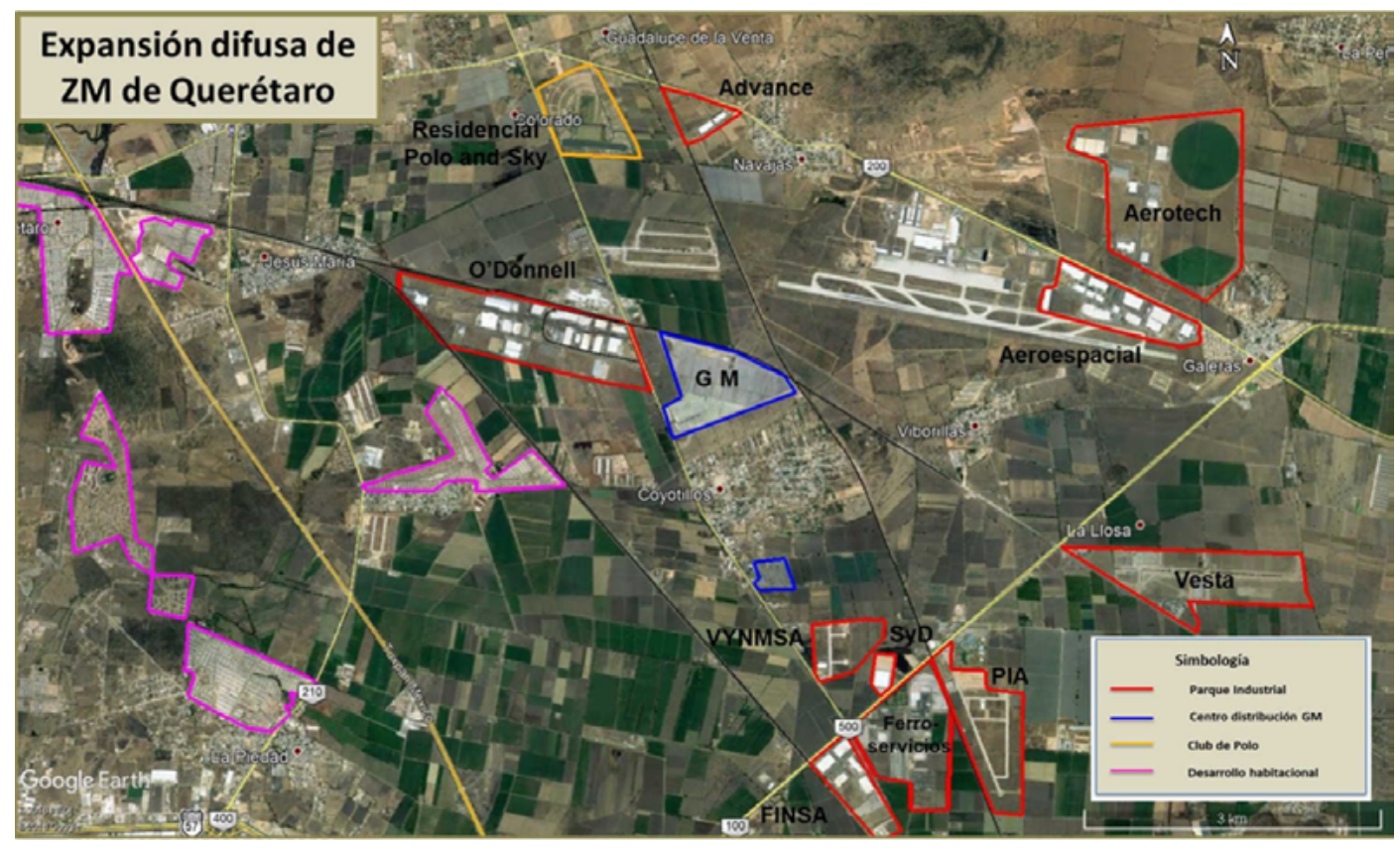

Fuente: elaboración propia con base en levantamiento en campo, 2018.

grandes franjas de tierras cultivadas, con centros de distribución y actividades logísticas tales como Ferroservicios (figura 4) y centro de distribución de GM-General Motors en El Marqués (en parte del ejido de Coyotillos), al igual que establos de ganado (figura 5), con otras áreas agrícolas ejidales y de propiedad priva$\mathrm{da}$, con parques industriales de reciente creación (figura 6), tierras de agostadero, desarrollos residenciales de vivienda para diferentes estratos sociales, una veintena de localidades rurales originales dispersas donde desarrollaron sus centros de población los diversos ejidos de los municipios de Colón (Galeras, Viborillas, La Esperanza, San Vicente el Bajo y San José de la Peñuela, entre otros) y El Marqués (Navajas, Coyotillos, Jesús María, La Piedad y Guadalupe La Venta) e incluso con el desarrollo de una universidad privada con áreas de residencias, servicios y comercio en medio de otros predios rurales, en una sucesión de usos cambiantes y flexibles, que pareciera no responder a criterios de ordenamiento territorial o de planeación urbana-regional coherente, sino más bien a la lógica de un mercado inmobiliario 


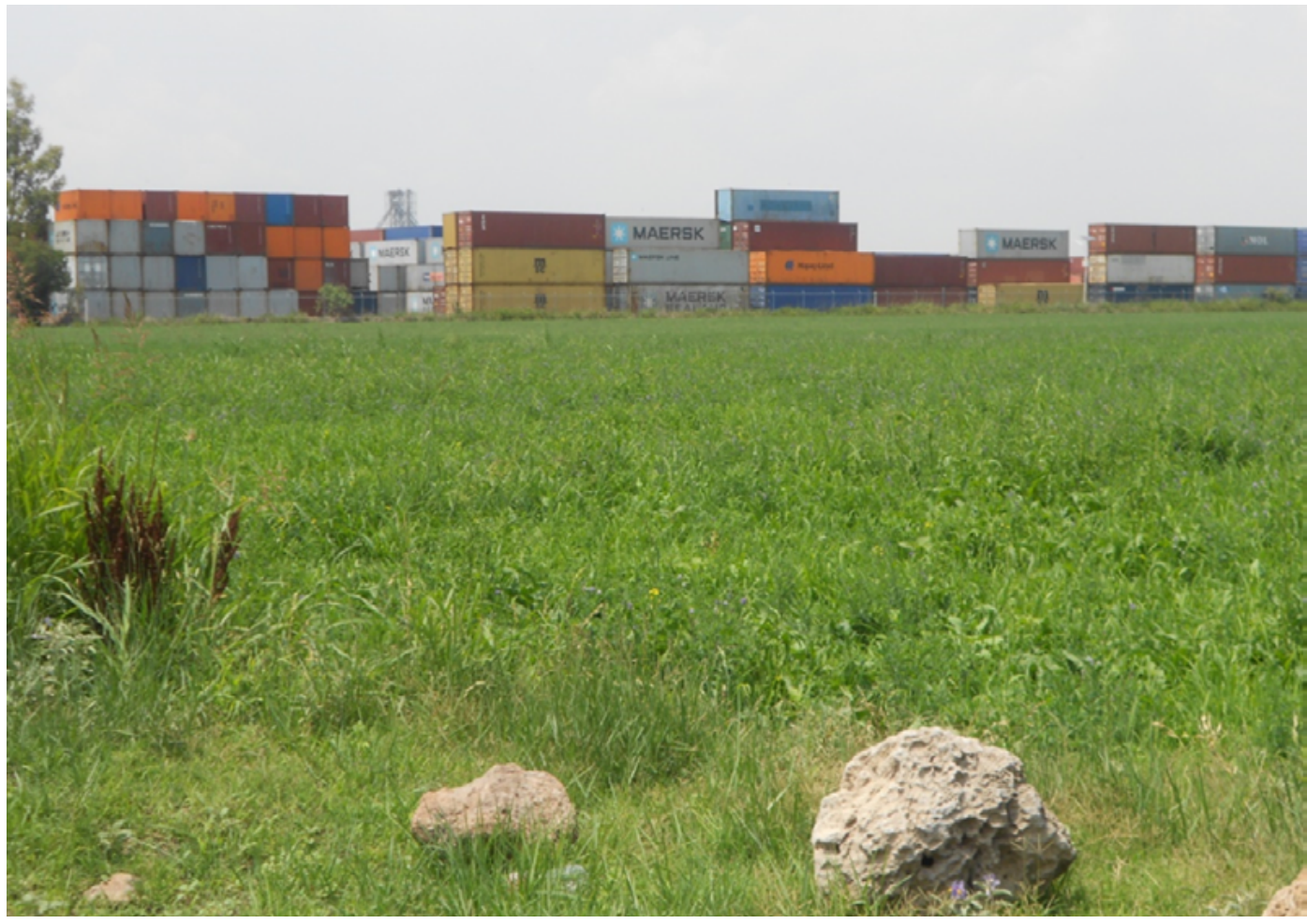

Fuente: Montes (2016).

financiariazado, altamente especulativo, enfocado en la rentabilidad inmediata de sus inversores, antes que en el desarrollo local, ambiental y socialmente sostenible a largo plazo.

Al respecto, estudios y referencias previas evidencian la debilidad de los mecanismos formales de planeación respecto al creciente poder de un sector inmobiliario financiarizado que incide cada vez más en la configuración del espacio regional. Montes (2016) muestra cómo los diversos planes parciales de desarrollo urbano en El Marqués y Colón han ido a remolque del vertiginoso cambio en los usos del suelo de esos municipios y requieren de actualizaciones periódicas ante la velocidad de los cambios.

Por su parte, Jiménez (2010) y González \& Martner (2011) muestran el desfase entre una acelerada urbanización del campo con desarrollos inmobiliarios que rebasan constantemente la planeación formal (planes y programas urbano-regionales), tersitorios 43-Especial 


\section{territorias 43-Especial} 20

Figura 5. Establo de la localidad de San Vicente el Bajo, Colón

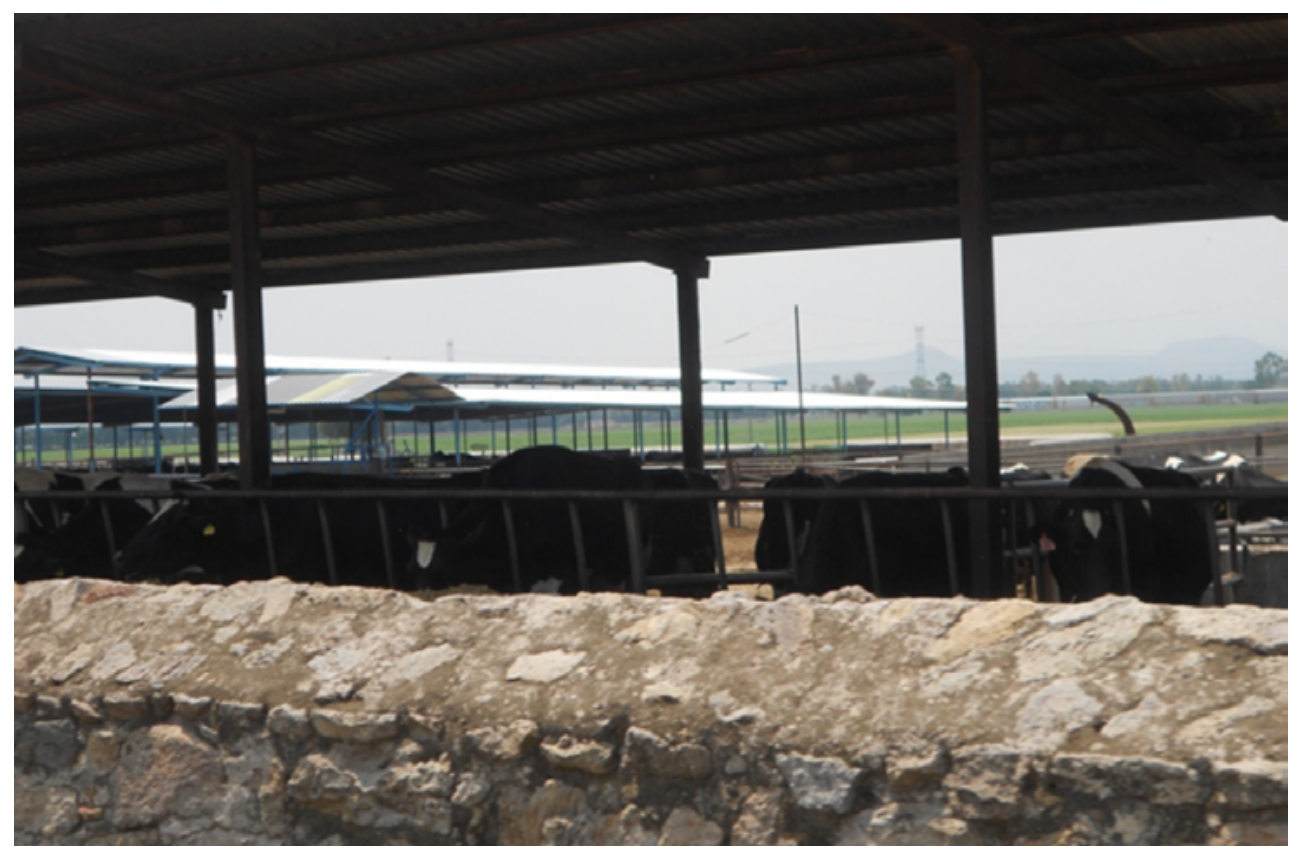

Fuente: Montes (2016).

afectando particularmente a una infraestructura de caminos superada por el rápido crecimiento de los flujos de transporte de mercancías (camiones tipo trailer cada vez más grandes y numerosos) y personas, cuyo desarrollo no fue previsto como un elemento primordial en la llamada microrregión de Navajas-Galeras, ubicada en los territorios de El Marques y Colón.

Si bien es cierto que en Querétaro existe un organismo encargado de la planeación urbana y regional, también lo es que, en paralelo, hay otras dos instancias que toman decisiones sobre la autorización de actividades y los cambios de uso del suelo. Por una parte, aquella encargada de la promoción de actividades económicas y la atracción de inversiones en el Estado de Querétaro, la cual revisa y autoriza los proyectos de desarrollos industriales, comerciales y de servicios que presentan inversionistas privados y desarrolladores inmobiliarios, con criterios propios que no necesariamente han estado alineados con los de la planeación urbano-regional de la zona. Pero,

más independiente aún es la actuación de los municipios involucrados en la zona de estudio, que tienen plena jurisdicción para

Carlos Daniel Martner-Peyrelongue 
Figura 6. Parque Industrial Vesta Park, Colón

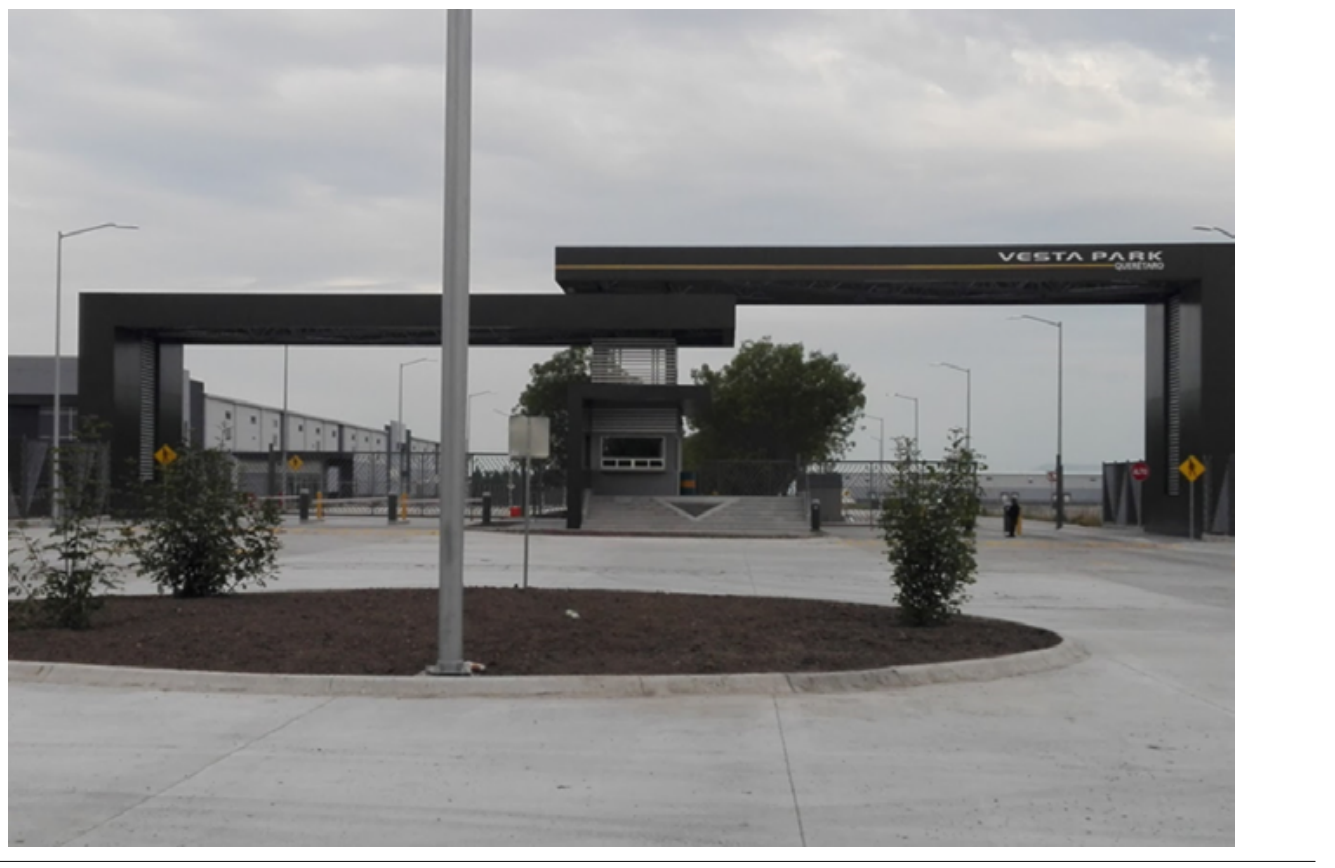

cambiar los usos del suelo a través de sus respectivos Cabildos, cuando hay solicitudes concretas de agentes económicos privados. Es evidente que las necesidades y prioridades de los gobiernos municipales son distintas a las de las otras instancias estatales, sobre todo tratándose de municipios con escasos recursos, donde la posibilidad de realizar cambios de suelo rural a suelo de tipo industrial, comercial, habitacional o de servicios va a significar un incremento sustancial de los ingresos del Ayuntamiento vía impuestos (predial, aprovechamientos, etcétera) (Martner, 2016, pp. 53-54)
En este sentido, De Mattos y Fuentes (2012) señalan que,

otro de los factores fundamentales de estos cambios en la forma urbana tiene que ver con los nuevos arreglos institucionales impulsados por la nueva gobernanza neoliberal, donde el mercado juega un rol central y el espacio urbano se encuentra altamente mercantilizado (p. 1).

A la mercantilización del suelo rural y la desregulación del mercado hipotecario, "se sumaron la flexibilización del planeamiento y la progresiva sustitución de los territorias 43-Especial 


\section{tersitarias de residencia a sus centros de trabajo, educación, servicios, comercio, etc.} 43-Especial planes reguladores por una multiplicidad de proyectos urbanísticos que renunciaron a definir un modelo de ciudad" (Méndez, 2018 , p. 327) y de territorio.

Lo cierto es que la acción de estos actores vinculados a los procesos de financiarización ha contribuido a la transformación territorial acelerada de Querétaro y, en particular, de Colón, con afectaciones de diversa índole en el ámbito local y regional, que todavía no han sido del todo cuantificadas, tales como el encarecimiento del suelo rural y el desplazamiento de los pobladores originarios más pobres hacia comunidades rurales más alejadas, y la desposesión del suelo rural de muchos ejidatarios que, si bien es cierto, en principio obtuvieron un caudal importante de dinero por la venta de sus tierras, en el mediano y largo plazo no queda tan claro cuál será su ocupación ni fuente de ingresos.

Otro problema derivado de la expansión difusa de este nuevo modelo territorial deriva de la necesidad de articular esta dispersión en el espacio mediante el desarrollo, por parte del Estado, de múltiples vías de comunicación de altas especificaciones y servicios de transporte suficientes para soportar una intensificación de la movilidad de la población que tiene que realizar recorridos cada vez más largos para acceder desde sus lugares o localidades
Existe un intenso flujo de automóviles de profesionistas, gerentes y empleados de rango medio y superior que diariamente se desplaza entre la ciudad de Querétaro y las zonas industriales, comerciales y de servicios de la zona de estudio, mientras que buena parte de los obreros y empleados de baja calificación se mueven de las localidades rurales tanto hacia los núcleos industriales dispersos en el campo, como hacia actividades de servicio, muchas veces informales, que realizan en la ciudad, tal como se constató en trabajos previos (Martner, 2015; 2016). Precisamente, la congestión vehicular del campo a causa de su limitada infraestructura de caminos y carreteras ha propiciado la construcción de ampliaciones en este tipo de infraestructura para darle viabilidad, aunque sea a corto plazo, a esta configuración territorial emergente.

En efecto, tal como señala Méndez (2018),

las grandes inversiones públicas en infraestructuras de transporte facilitaron la movilidad y mejoraron la accesibilidad de nuevos territorios disponibles para la promoción inmobiliaria. [De esta forma], ... junto con la compactación de las áreas centrales, se produjo una acelerada expansión periférica de límites difusos, generadores de una creciente fragmentación social espacial (p. 327).

Carlos Daniel Martner-Peyrelongue 


\section{Reflexiones finales}

De acuerdo con el análisis presentado, existe evidencia relevante de la acelerada metamorfosis urbano-regional propiciada por la financiarización del modelo territorial en la región de Colón, la cual forma parte de la expansión de la ciudad intermedia mexicana de Querétaro. En este sentido, se ha consolidado un creciente proceso de mercantilización de una modalidad de desarrollo territorial extendido, que combina y mezcla usos del suelo muy disímiles, bajo un esquema en el que, "el capital financiero se transformó de capital real bajo la forma de activos inmobiliarios, que a su vez se convirtieron en una fuente de generación de plusvalías financieras" (Méndez, 2018, p. 328), donde la regulación de los usos del suelo y planeación urbano-regional se ve rebasado por los criterios de rentabilidad de los FIBRA, los certificados bursátiles inmobiliarios y otros instrumentos del capitalismo financiarizado que prima en la actualidad.

Así es como, durante la última década y media, se ha producido una yuxtaposición de áreas construidas ex-novo, sobre el hábitat rural preexistente, donde se desarrollan polígonos industriales, centros de distribución y de servicios logísticos, zonas residenciales y comerciales y vías de comunicación en torno a localidades rurales de larga data y espacios agrarios todavía vigentes y viables. Así, la ciudad, tal y como era concebida previamente, entra en crisis, y ahora cabría sustituir la idea de la ciudad como un núcleo construido de manera más o menos continua en el espacio, por el de ciudad difusa, fragmentada y extendida, lo cual supone la consideración tanto de la población central como la de toda la orla periurbana y rural intensamente conectadas con ella por flujos cotidianos, ya sea laborales o de otra índole (Formigo \& Aldrey, 2005).

De esta manera, la búsqueda de nuevos espacios para incorporar al negocio inmobiliario esta ciudad intermedia mexicana,

aceleraron una expansión metropolitana carente por lo general de un plan preestablecido, lo que favoreció la multiplicación de actuaciones dispersas. Se rompió así la continuidad entre segmentos de la aglomeración, provocando crecientes problemas de conectividad, así como elevados costes económicos, sociales y ambientales derivados de la movilidad diaria forzada (Méndez, 2018, p. 328).

En definitiva, el resultado de este proceso está conduciendo a una ocupación anárquica del territorio, donde las premisas de rentabilidad de los inversores sustituyen, en buena medida, los criterios de una planeación urbana-regional sostenible, que privilegie el desarrollo local y ambiental a largo plazo, con afectaciones de diversa índole para el ámbito local y regional, que todavía no han sido del todo cuantificadas, pero que generan un amplio campo de estudios futuros. Sin duda, todavía hay territarios 43-Especial 
mucho trabajo por hacer hacia adelante, tanto en el análisis de las nuevas desigualdades socioterritoriales y afectaciones ambientales generadas por este modelo, como en la búsqueda y elaboración de alternativas viables para contrarrestar esta forma de ocupación rapaz del territorio.

\section{Referencias}

Álvarez, G. (2011). Estructura y temporalidad urbana de las ciudades intermedias en México. Frontera Norte, 23(46), 91-124. http://www.redalyc.org/articulo.oa?id=13619212004

Amin, A., \& Thrift, N. (2002) Cities: Reimagining the urban. Wiley.

Anzaldo, C., \& Rivera, A. (2006). Evolución demográfica y potencial de las ciudades de México. En Consejo Nacional de Población (CONAPO), La situación demográfica en México 2006 (pp. 207-231). CONAPO. http:// www.conapo.gob.mx/es/CONAPO/ La_situacion_demografica_de_Mexico_2006

Brenner, N. (2013) Tesis sobre la urbanización planetaria. Nueva Sociedad, (243), 38-66. https://nuso.org/articulo/ tesis-sobre-la-urbanizacion-planetaria/

Brenner, N., \& Schmid, C. (2016) La “era urbana" en debate. EURE, 42(127), 307-339. http://www.eure.cl/index. php/eure/article/view/2123/926
Celis, F. (2017) ¿Qué son y cómo funcionan las Fibras? Forbes. https://www.forbes.com.mx/que-son-las-fibras/

Consejo Estatal de Población (COESPO). (2017). Información demográfica municipal (Querétaro, Corregidora, El Marques, Colón). Coespo/Gobierno del Estado de Querétaro.

Consejo Nacional de Población (CONAPO). (2011). Delimitación de las Zonas Metropolitanas de México 2010. CONAPO/ Secretaría de Gobierno.

Daher, A. (2013). Territorios de la financiarización urbana y de las crisis inmobiliarias. Revista de geografía Norte Grande, (56), 7-30. https://doi.org/10.4067/S071834022013000300002

Delgadillo, V. (2016) Financiarización y mercantilización del desarrollo urbano en escala planetaria. Entrevista a Carlos A. de Mattos. Andamios, 13(32), 213-243.

Delgado, J. (1998). Ciudad-Región y transporte en el México Central. Plaza \& Valdez.

Espino, G. (1995). La población flotante de la ciudad de Querétaro. Revista Sociología (Querétaro), 10, 48-59.

Formigo, J. \& Aldrey, J. (2005). Periurbanización y rururbanización en Galicia. http://www.cervantesvirtual.com/ obra/periurbanizacin-y-rururbanizacin-en-galicia-0/

González, O., \& Martner, C. (2011). Efectos socioterritoriales del Aeropuerto 
Internacional de Quevétaro y del Complejo Aeroespacial en la Microrregión Metropolitana de Querétaro y municipios colindantes al AIQ. Segundo Informe Técnico. Proyecto FOMIX. Gobierno del Estado de Querétaro-Consejo Nacional de Ciencia y Tecnología (Conacyt).

Harvey, D. (2012) El enigma del capital y las crisis del capitalismo. Akal.

Instituto Nacional de Estadística y Geografía (INEGI). (2017). Anuario estadistico y geográfico de Querétaro 2017. INEGI.

Instituto Nacional de Estadística y Geografía (INEGI). (2018). Producto Interno Bruto por Entidad Federativa 20032017. INEGI.

Jiménez, E. (2010) Efectos potenciales de la articulación fallida de los flujos de transporte en los Planes de Desarrollo Urbano: caso microrregión Navajas-Galeras, Querétaro, México. Memorias del XI Seminario de la Red Iberoamericana de Investigadores sobre Globalización y Territorio (RII), Mendoza: UnCUYO.

Lefebvre, H. (1983) La revolución urbana. Alianza Editorial.

Martner, C. (2015) Transporte y articulación urbano-rural de una ciudad intermedia mexicana. Revista Mexicana de Sociologia, 77(2), 215-241. http://dx.doi.org/10.22201/ iis.01882503p.2015.2.48223

Martner, C. (2016) Expansión dispersa, ciudad difusa y transporte el caso de Querétaro, México. EURE, 42(125),
31-60. https://dx.doi.org/10.4067/ s0250-71612016000100002

de Mattos, C., \& Fuentes, L. (2012). Crecimiento de la población de Santiago entre 2002 y 2012: ‘compactación o expansión? Una falsa disyuntiva. Planeo, 8. http://revistaplaneo.uc.cl/ planeo-academia/articulos-centrales/ crecimiento-de-la-poblacion-de-santiago-entre-2002-y-2012-compactaciono-expansion-una-falsa-disyuntiva/

de Mattos, C. (2016). Financiarización, valorización inmobiliaria del capital y mercantilización de la metamorfosis urbana. Sociologias, 18(42), 24-52. https://doi.org/10.1590/15174522018004202

Méndez, R. (2018) La telaraña financiera. Una geografía de la financiarización y su crisis. RiL Editores.

Montes, E. (2016) Movilidad y cambios de usos de suelo en la microrregión $\mathrm{Na}$ vajas- Galeras. (Tesis de licenciatura, Universidad Autónoma de Querétaro).

Pradilla, E. (1984). Contribución a la critica de la teoría urbana. Del espacio a la crisis urbana. Editorial Universidad Autónoma Metropolitana.

Procuraduría Agraria (2009). Glosario de términos juridicos-agrarios, Ciudad de México. http://www.pa.gob. $\mathrm{mx} / \mathrm{pa} / \mathrm{conoce} / \mathrm{publicaciones} / \mathrm{Glo}-$ sario $\% 202009 /$ GLOSARIO $\% 20$ DE $\% 20$ T \% C 3 \% 8 R M IN OS $\% 20$ JUR\%C3\%8DDICO-AGRARIOS\%20 2009.pdf tersitarios 43-Especial 
Sánchez, A., \& Propin, E. (2001). Cambios en la orientación funcional de las ciudades medias del trópico mexicano. Cuadernos Geográficos, (31), 69-85. http://www.redalyc.org/articulo. oa? id=17103104

Veltz, P. (2014). Mondialisation, villes et territoires: Une économie d'archipel. Quadrige. 